\title{
Vacunar al personal de salud de los geriátricos redujo la mortalidad de los pacientes
}

Effects of influenza vaccination of health care-workers on mortality of elderly people in long term care: a randomized controlled trial. Carman FW, Elder AG, Wallace LA, et al. Lancet 2000; 355: 93-97

\section{Objetivo}

Definir si la vacunación antigripal al personal de salud (PS) de hospitales geriátricos de cuidados crónicos reduce la mortalidad y la frecuencia de gripe, virológicamente comprobada, de los pacientes internados.

\section{Diseño}

Estudio de grupos paralelos, ${ }^{*}$ aleatorizado y controlado.

\section{Lugar}

Reino Unido.

\section{Participantes}

PS (incluyendo los de servicios auxiliares) de 20 hospitales geriátricos (capacidad de 44 a 105 pacientes) que brindaban consentimiento informado; y 1437 pacientes de dichos establecimientos.

\section{Intervención}

Se aleatorizaron (por racimos o clusters*) los hospitales para que oferten o no la vacuna antigripal aL PS. Se intentó que los hospitales de ambos grupos fueran similares en cuanto al número de camas y política de vacunación a pacientes (la mitad de los hospitales vacunaban sistemáticamente). Se realizó vigilancia virológica de una muestra aleatorizada del $50 \%$ de los pacientes mediante hisopados nasales y fauciales (testeados para influenza tipo A y B) tomados cada dos semanas durante el período epidémico. También se hisopó oportunísticamente a pacientes no aleatorizados con Fuente de financiamiento: No referida cuadro tipo gripal. El grado de vacunación del PS de hospitales que no ofrecían la antigripal se valoró con cuestionarios anónimos.

\section{Medición de resultados principales}

Mortalidad de los pacientes durante los 6 meses de la estación gripal '96‘97. Tasa de infección por gripe (comprobada).

\section{Resultados principales}

Se vacunó el 50,9\% de los 1217 trabajadores de hospitales en los que se ofrecía la vacuna (HV) vs el $4,9 \%$ en los que no se hacía (HNV). La edad media de los pacientes ( 82 años) y el sexo (30\% hombres) fue similar, pero fue diferente el puntaje medio de discapacidad de Barthel (HV: 5 vs HNV: 3) y la proporción media de pacientes vacunados (HV: $48 \%$ vs HNV:33\%). La tasa de mortalidad no corregida fue 13,6\% (102/749 pacientes) en HV vs $22,4 \%(154 / 688)$ en HNV: OR 0,58 (IC95\% 0,4-0,84; $p=0,014)$ y OR ajustando por edad, sexo, vacunación a pacientes y discapacidad 0,61 (IC95\% 0,36-1,04; $\mathrm{p}=0,092$ ). La proporción de pacientes positivos para influenza no varió entre grupos ( 5,4 vs $6,7 \%$ respectivamente). Ninguna de las 17 necropsias de HV fue PCR+ vs el 20\% (6/30) de HNV $(p=0,055)$.

\section{Conclusiones}

La vacunación del PS se asoció a una significativa reducción de la mortalidad de los pacientes, aunque no se asoció a una reducción de las infecciones gripales no fatales.

\section{COMENTARIO}

La gripe es una importante causa de mortalidad en mayores de 65 años. El riesgo de infección y complicaciones es particularmente alto entre los ancianos frágiles de hospitales geriátricos.

De hecho la mitad de los pacientes que mueren por gripe y patologías crónicas tienen más de 75 años y el $50 \%$ de las muertes ocurren en pacientes en cuidados geriátricos. ${ }^{1}$ Estudios caso-control mostraron que la vacunación en este grupo reduce el riesgo de neumonía y muerte ${ }^{2}$ constituyendo una indiscutible recomendación. ${ }^{3}$ Llama la atención que sólo la mitad de los centros hayan adoptado la recomendación de vacunar sistemáticamente a estos pacientes. Lamentablemente este grupo de alto riesgo tiene una protección incompleta debido a la pobre respuesta inmune (los brotes de gripe pueden ocurrir aún con un $85 \%$ de vacunación de pacientes y $40 \%$ de las enfermeras). ${ }^{1}$ Por esta razón, además de considerar drogas antivirales, ${ }^{3}$ resulta interesante la estrategia adicional de cortar la transmisión nosocomial a través de la vacunación del PS. En el estudio piloto del actual (12 centros y 1059 pacientes) ${ }_{1}^{4}$ la vacunación del PS de hospitales geriátricos se asoció a una reducción del 17 al 10\% en la mortalidad de los ancianos durante el invierno. No se redujeron las infecciones respiratorias bajas (virológicamente negativas para influenza) y sólo el $5 \%$ de los no vacunados seroconvirtieron para influenza, por lo que no hubo evidencias directas de la efectividad de la estrategia. Las principales fortalezas del presente estudio son el diseño aleatorizado, el prolijo cálculo del tamaño muestral (basado en un estudio piloto) y el duro resultado evaluado: mortalidad. Sin embargo antes de aceptar sus conclusiones deben tenerse en cuenta posibles confundidores* como la mayor discapacidad y grado de vacunación de Los pacientes de HV y debilidades como la falta de datos de gripes o muertes asociadas a neumonías. Aunque la discapacidad es un fuerte predictor de complicaciones fatales en ancianos, las diferencias basales no eran muy marcadas (favoreciendo en todo caso a los HNV) y es improbable que con-

tribuyan de manera importante a las diferencias de mortalidad teniendo en cuenta que los resultados apenas se modifican tras el ajuste por dicha variable. Las diferencias en la vacunación de pacientes fue inesperada dado que se estratificaron los hospitales por régimen de vacunación a pacientes. Una explicación posible sería que Los programas de vacunación al PS hayan inducido a una mayor vacunación de los pacientes de esos centros. Si bien al ajustar por vacunación a pacientes los resultados permanecen estables, éstos podrian alterarse de corregirse la importante dispersión de ciertos hospitales y además, ajustando por otras variables como edad, sexo, vacunación a pacientes y discapacidad, la magnitud del efecto es similar pero estadísticamente no significativa. Por otro lado el sistema de vigilancia virológica (que desafortunadamente no incluyó al PS) no detectó diferencias en la tasa de gripe confirmada entre HV y HNV. Probablemente muchos casos no se confirmaron pues la vigilancia no abarcó toda la estación gripal (sólo la epidémica) o porque se resolvieron durante el período interhisopado, resultando en una tasa de detección de sólo 6,5\% en lugar del 25\% esperado. Esta menor detección restó considerable poder estadístico* para evidenciar diferencias entre grupos. Aunque en los casos fatales sí pudieron evidenciarse, dado el bajo número de eventos, este estudio no alcanzó confirmar la interrupción de la transmisión como protectora. Pareciera sumarse cierta evidencia a favor de la estrategia complementaria de vacunar al PS de hospitales geriátricos, que potencialmente podría beneficiar tanto al PS (ausentismo) como al los pacientes. Los programas de vacunación antigripal al PS de hospitales geriátricos en EE.UU., 5 alcanzan un $50 \%$ de cobertura, tal como en el presente ensayo. Quizás el impacto en la transmisión sería mayor con una mejor cobertura del PS pero esto debería corroborarse en nuevos estudios aleatorizados con mayor poder estadístico para detectar casos confirmados y complicaciones por gripe, tanto en pacientes como en el PS, contemplando la costo-efectividad de la estrategia.

Dr. Agustín Ciapponi *Ver Glosario

1. Nicholson, KG. Should staff in long-stay hospitals for elderly patients be vaccinated against influenza? Lancet 2000;355: 83-84.

2. Gross PA, Hermogenes AW, Sacks HA, et al. The efficacy of influenza vaccine in elderly persons: a meta-analysis and review of the literature. Ann Intern Med 1995, 123:518-27.

3. Rubinstein F, Gimpel N, Ciapponi A, Guía de Práctica Clínica. Influenza (Gripe): prevención y tratamiento. Videncia en Atención Primaria, Enero Febrero 2000 , Vol 3 No1:22-23.

4. Potter J, Stott DJ, Robrts MA, et al. Influenza vaccination of health care-workers in long term care hospitals reduces the mortality of elderly persons. J Infect Dis 1997,175:1-6. 5. Thomas DR, Winsted B, Koontz C. Improving neglected influenza vaccination among healthcare workers in long term care. J of Am Geriatr Soc 1993; $41: 928-30$. 